\title{
Distinto, diferente o una crítica del plagio
}

Bien puede argumentarse que la originalidad es el bastión fundamental de la publicación académica, esto es, del proceso mediante el cual un nuevo descubrimiento científico es inducido al acervo de conocimiento existente en una determinada disciplina. En efecto, ante un descubrimiento o invención ocurrido como resultado de un proceso riguroso de investigación, revisión o reflexión, el sentir altruista del científico lo motiva a compartirlo con la comunidad que le atañe. Y el mecanismo adoptado para tal fin, desde que se da inicio en el siglo XVII a la publicación académica, es divulgar la primicia de un artículo académico en una revista científica especializada. La inclusión de dicha primicia en la literatura, dependerá del mérito que juzguen pares acreditados para ello (editores, evaluadores, árbitros, correctores, y finalmente lectores conocedores), y su impacto será medido por el reconocimiento que la misma comunidad le otorgue al mencionarlo en conferencias, aulas, cátedras, convenciones y por supuesto, en artículos, patentes y demás productos científicos.

Sorprende pues, encontrar autores que desconozcan dicho principio, y que busquen vulnerarlo al intentar publicar primicias ajenas o propias, previamente incorporadas a la literatura. Asombra aún más que no sea cuestión de casos aislados, sino de reiteradas ocasiones, como hemos podido constatar recientemente dentro de nuestro proceso de revisión arbitrada. Afortunadamente la extrema pericia de nuestros editores y evaluadores nos ha permitido frustrar tales intentos ignominiosos de divulgación de material no original o duplicado en nuestras páginas. Vale resaltar que el agravante de este fenómeno, es que no solamente infringe los derechos morales del autor original, sino los derechos de reproducción de la publicación original. De allí que debamos asumir cero tolerancia con su ocurrencia.

Las argucias varían desde lo relativamente inocente hasta lo altamente sofisticado. La ocurrencia más habitual que hemos encontrado es la reproducción de párrafos ajenos transcritos literalmente sin cita textual sino como cita indirecta (referencia bibliográfica); esto desconoce la autoría original de la frase o el párrafo, atribuyéndolo engañosamente, como si fuera propio (no solo para textos, también ocurre en gráficas y tablas). Casos alarmantes se han encontrado, donde en un mismo artículo, numerosos párrafos son copiados (cuatro o cinco). Incluso, donde páginas enteras ajenas (hasta dos o tres) son re- 
producidas sin ningún desparpajo. Algunas veces se utiliza como artimaña la inclusión de material traducido del inglés, como si la mera traducción literal desde otro idioma, despojara de su crédito al autor original. La presunta ingenuidad de este fenómeno, quizás apunte a la necesidad de fortalecer nuestra labor de pedagogía en comunicación científica dentro nuestras aulas de pregrado y posgrado.

Un segundo patrón, menos cándido que el anterior, consiste en la paráfrasis de textos no propios, en menor o mayor extensión sin siquiera citación bibliográfica; un caso similar es el "reciclaje" de material propio sin modificación ni mención a las publicaciones anteriores donde haya sido presentado originalmente. De otra parte un tercer tipo, de mayor gravedad, lo constituyen artículos armados como rompecabezas de extractos de publicaciones propias y ajenas no referenciadas, y que admirablemente alcanzan algún grado de congruencia a pesar de su falta de vigencia, intencionalidad u originalidad.

Es preocupante la tendencia de crecimiento del fenómeno que hemos evidenciado en los últimos seis meses. A manera de ilustración, en un grupo de once artículos recibidos en una convocatoria para una edición especial con reflexiones sobre líneas de investigación, cinco (casi la mitad) fueron rechazados por anomalías de ese tipo. Otro ejemplo de naturaleza patológica que se destaca, fue un manuscrito recibido en nuestra convocatoria regular, que en realidad correspondía a una traducción completa a español de otro previamente publicado en inglés por los mismos autores en una revista colega; la publicación de una traducción no es en sí mismo censurable, siempre y cuando sea manifestado, y consentido por, el editor, lo cual no ocurrió en este caso (los autores diligentemente firmaron carta de originalidad). El editor asignado no solo de manera acertada detecto el potencial engaño, sino que advirtió además que esa publicación previa en español imitaba inquietantemente a trabajos antiguos de otros autores publicados cinco y diez años atrás, copiando su estructura y transcribiendo contenidos originalmente en inglés. Este caso constituye una instancia de reciclaje intensivo y plagio bilingüe alternado: mezcla de material publicado en inglés de diferentes fuentes no propias, que luego se publica en español sin las debidas atribuciones y que posteriormente se intenta publicar nuevamente traducido al inglés, en una ventana de tiempo cercana a la década, sin alteración o actualización significativa del contenido. Un verdadero contra-ejemplo que demuestra la sofisticación que han logrado las estratagemas de apropiación indebida de creaciones ajenas (vale la pena resaltar que como buena práctica de ética editorial, debidamente notificamos al editor general de la otra revista sobre el amargo hallazgo).

Podríamos mencionar mucho mas casos; justo en el momento de escribir esta nota acabamos de identificar un caso de duplicación fragmentada: un artículo recién publicado en otra revista amiga, que copia la estructura, organización y algunos extractos literales de otro artículo anteriormente publicado en nuestra revista, cambiando solo la técnica y datos similares sin citar siquiera la publicación previa, o hacer referencia a ella para contrastar resultados nuevos, en una evidente atribución indebida de originalidad, aun así se trate de los mismos autores ${ }^{1}$ (cabe anotar igual, que el hallazgo ha sido compartido con la editora de la revista amiga). Otro más, que excede el ámbito de la Revista pero que da cuenta de la gravedad y proliferación de la mala práctica, es el caso recientemente conocido por el país de un honorable senador de la república que en la redacción del proyecto de Ley 082 de 2014 sobre disposiciones para el

\footnotetext{
${ }^{1} \mathrm{Y}$ sin embargo desde una perspectiva científica, resulta de alguna forma gratificante poder corroborar en la práctica lo definido en la teoría, pues todos los casos antes mencionados corresponden en efecto a la caracterización del plagio dada por Steven Shafer en recientes notas editoriales (ver "Yo will be chaught" (2011), Anesthesia \& Analgesia, Vol. 112, Issue 3, p 491-493, y “Plagiarism Is Plagiarism Is Plagiarism” (2014), Vol. 118, Issue 1, p $1-2)$.
} 
código de ética de los funcionarios públicos (!), copió sin citar, ni sonrojarse, material del portal “El Rincón del Vago” en Internet ${ }^{2}$.

Frente el angustioso incremento de esta práctica indebida, volviendo a nuestra crítica, se hace necesario vigorizar los esquemas de protección que garanticen la originalidad y no duplicidad de las primicias científicas. Hacemos un llamado para estrechar los lazos de colaboración entre revistas afines. Urge fortalecer la mesa de trabajo de ética y malas prácticas de la Red Colombiana de Revistas de Ingeniería - RCRI. Proponemos mantener repositorios compartidos de manuscritos en evaluación, recomendaciones de no publicación, reportes de casos de conductas no éticas, listas de autores vetados. Valdría la pena compaginar esfuerzos, armonizar procedimientos y estandarizar sanciones relativas a la cero tolerancia con el plagio. Lo que a propósito, pone nuevamente sobre la palestra la discusión en relación a la posibilidad de unificar revistas y construir sobre fortalezas dispersas (ver nuestra Nota Editorial Vol. 18, Num. 1, 2013).

Por otra parte, recomendamos revisar y acoger las guías que han sido propuestas por consorcios académicos internacionales, pues para consuelo de tontos, el fenómeno es un mal que se propaga por todas las latitudes (ver por ejemplo los flujogramas del código de buena conducta propuesto por el Committee of Publication Ethichs - $\mathrm{COPE}^{3}$ ). Igualmente reiteramos nuestro clamor para que la labor que con buen juicio, suspicacia y dedicación realizan los editores y árbitros comprometidos con la divulgación de la ciencia, sea reconocida oficialmente dentro de nuestros planes de trabajo y ejercicio profesional (tema previamente referido en nuestra Nota Editorial Vol. 18, Num. 2, 2013).

Ahora bien, la avalancha de publicaciones en línea y la apertura de medios para consulta bibliográfica en tiempo real, implican una limitación práctica en la capacidad de detección de los revisores humanos y hace incuestionable la necesidad de mecanismos automatizados para filtrado anti-plagio; software del estilo TurnitinTM (iParadigms LLC., Oakland, California) o URKUNDTM (PrioInfo AB., Estocolmo, Suecia) deben ser incluídos dentro de la caja de herramientas básicas suministradas a editores, revisores y los mismos autores, por parte de universidades y editoriales académicas. La optimización de la utilización de estos servicios, y los costos que ello acarrea, constituyen nuevamente un interesante foco de convergencia para todas las revistas afiliadas a la RCRI y en general a los medios de publicación científica en el país. Valga la aclaración que en particular, INGENIERÍA en la actualidad carece de acceso a estos recursos. Y por supuesto, ninguno de estos esfuerzos sería suficiente sin la colaboración última de todos los lectores, quienes con su experticia y perspicacia son los filtros mas rigurosos para detectar y censurar conductas anti-éticas que merezcan ser castigadas con el escarnio académico público.

Ante este panorama corresponde pues tomar medidas de urgencia; la más inminente es definir y adoptar una línea editorial anti-plagio, que queremos dar a conocer aprovechando este espacio (la política completa se puede consultar en nuestra página Web): las acciones que serán tomadas en adelante, en caso de sospecha razonable de intento de publicación de material no original o duplicado, y que dependerán de la gravedad de la falta conforme el dictamen del Comité Editorial y/o Científico irán desde amonestación mediante comunicación privada o pública a través de páginas editoriales, pasando por divulgación de la falta en Comité de Ética y de Regulación Profesional de alcance nacional e internacional (como RCRI y COPE), notificación a las entidades de afiliación institucional de los autores o financiadores, editores

\footnotetext{
${ }^{2}$ Consultado en Internet: http://www.semana.com/Imprimir/408386 (ultima visita: Noviembre 24, 2014).

${ }^{3}$ Disponible via Web en: http://publicationethics.org/resources/flowcharts (ultima visita: Noviembre 24, 2014).
} 
y revisores, contemplando solicitud de corrección o inclusive retractación y retiro del artículo de nuestros archivos y de bases de datos e índices bibliográficos en donde se encuentre indizada la Revista, y llegando hasta el veto de publicación para los autores por un periodo de hasta cinco años y denuncia ante las autoridades competentes, en caso que el buen nombre de la Universidad Distrital se vea comprometido.

Buscamos de esta manera brindar a nuestros lectores y autores mayor confianza en que nuestras páginas propenderán por la defensa de la primicia y originalidad en la publicación académica. Y aunque sospechamos que el reto de defender la buena conducta en la literatura científica requerirá un esfuerzo mancomunado enorme, mas del que puedan garantizar los mecanismos y estrategias mencionados anteriormente, nuestro propósito es aportar al debate y unirnos a la causa. Quizás haciendo eco de algunas estrofas de un son de impecable factura en nuestro juicio, interpretado por la Afro-Cuban All Stars y de autoría de Juan de Marcos ${ }^{4}$, podamos transmitir de manera mucho mas armoniosa, graciosa y elegante el mensaje que aspirábamos expresar ${ }^{5}$. Bastaría con parafrasear el término música con el de artículo científico. Júzguenlo ustedes:

"Es muy difícil ver lo original, en estos tiempos en que todos se imitan, ya la diversidad no se ejercita, y en música muchos suenan igual.

$\mathrm{Y}$ en el arte se debe tener sello, algo que se distinga entre la gente, con imaginación crear lo bello y que sea distinto y diferente.

Porque en la vida se debe andar derecho, rendir tributo a quien se lo merece, con imaginación crear lo bello y que sea distinto, diferente.

$$
\text { (...) }
$$

Algo tiene que decir la música que se invente, pero si es buena y original ¡mas lo agradece la gente!”

Colofón. Agradecemos como siempre a los autores, revisores y editores que hicieron posible este número, con aportes sobre dispositivos de control de apuntador para personas discapacitadas, modelos de inventarios con deterioros, estudios de trazabilidad de abastecimiento de frutas, disquisiciones sobre la congestión peatonal en estaciones de transporte masivo, procesamiento de imágenes radiológicas para detección de nódulos cancerosos y una serie de reflexiones de investigadores del programa de doctorado de la Facultad de Ingeniería de la UD.

\section{Sergio A. Rojas, PhD. Editor General Revista INGENIERÍA}

\footnotetext{
${ }^{4}$ Gonzáles, Juan de Marcos y Villa, Lázaro, 1999, “Distinto, diferente”, en Distinto, diferente (CD), Londres, World Circuit.

${ }^{5}$ Respondiendo parcialmente al deber pedagógico aludido entrelineas, a lo largo de este escrito hemos reutilizado material ajeno y propio, cuyas fuentes han sido debidamente atribuidas utilizando diferentes modalidades: citas de apoyo o referencias a otros autores (menciones a editoriales en Anesthesia \& Analgesia), auto-citaciones (a editoriales en INGENIERIA), citación a material disponible en la Web y mención a marcas registradas y fabricantes. La inclusión de este último fragmento verbatim, tiene como segundo propósito ilustrar la utilización adecuada de citas textuales (nótese que al no tratarse de un artículo ordinario, las citaciones han seguido un formato de notas al pie de página, en vez de lista bibliográfica como exigen nuestras normas).
} 